\title{
Nonhomogeneous Oscillatory Vertically Stratified Flow Between Two Porous Plates
}

\author{
L. Prasanna Venkatesh, S. Ganesh and K.B. Naidu
}

\begin{abstract}
In this paper we consider the Nonhomogeneous oscillatory flow of a vertically stratified fluid between two vertical porous plates, induced by suction and injection at the porous walls. Within the frame work of Boussinesq approximation for density, complete solution is obtained using similarity transformation and interpreted. The axial and transverse velocity profiles and the pressure distributions are evaluated and illustrated in the figures. The results presented here add one more class of exact solution S.Ganesh [8] Rajagopal [14], Wang [22] to that of a few presently available in literature. The result for the axial velocity obtained here reduces to the result for the axial velocity in the case of laminar flow between parallel plates (i.e., when $v=0$ ).
\end{abstract}

Keywords--- Oscillatory Stratified Flow, Density Distribution, Stratification Parameter, Brunt - Vaisala Frequency, Boussinesq Approximation, Similarity Transformation

\section{INTRODUCTION}

$\mathrm{T}$ HE two dimensional steady state laminar flow in channels with porous walls has numerous applications in various branches of Engineering and Technology such as boundary layer control and transpiration cooling problems. It plays an important role in the study of problems which involve diffusion phenomena in a flowing gas stream.

Berman [4] was the first researcher who studied the problem of steady flow of an incompressible viscous fluid through a porous channel with rectangular cross-section, when the Reynolds number is low. He obtained a perturbation solution assuming normal wall velocities to be equal. Then Sellars [16] extended the problem studied by Berman when the Reynolds number is very high. Afterwards Yuan [20] and Terill [17] studied the problem for various values of suction and injection Reynolds numbers. Terill and Shrestha [18] have analysed the same problem, assuming different normal velocities at the walls.

Drake [6] has considered the flow of an incompressible viscous fluid in a long channel of rectangular section due to a periodic pressure gradient. Bagchi [5] has studied the unsteady

\footnotetext{
L. Prasanna Venkatesh, Assistant Professor, Department of Mathematics, Sathyabama University, Chennai, India, E-mail: prasannaclassof1@gmail.com

S. Ganesh, Professor \& Head, Department of Mathematics, Sathyabama University, Chennai, India, E-mail: sganesh19@yahoo.com

K.B. Naidu, Professor, Department of Mathematics, Sathyabama University, Chennai, India, E-mail: kbnaidu999@gmail.com
}

flow of visco-elastic Maxwell fluid with transient pressure gradient through a rectangular channel.

Forced Oscillation in an inviscid stratified fluid have been considered by many authors Krishna \& Sharma [9], Hendershott [9], Rao and Rao [7], Sharma and Naidu [13], Naidu [15] and Prasanna Venkatesh [10]. But very little work has been done on the oscillations in stratified viscous fluid.

We consider the oscillatory flow of a stratified fluid between two vertical porous plates, induced by suction and injection at the porous walls within the frame work of Boussinesq approximation for density.

\section{Formulation of the Problem}

The flow of an incompressible viscous fluid between two parallel porous plates $\mathrm{y}=0$ and $\mathrm{y}=\mathrm{h}$ along the direction of $\mathrm{x}$ axis is considered. It is assumed that there is a periodic injection of velocity $\mathrm{v}_{1} \mathrm{e}^{\text {iwt }}$ at the lower plate and periodic suction of velocity $v_{2} e^{i w t}$ at the upper plate where $v_{1}$ and $v_{2}$ are constants and $\omega$ is the frequency. Hence the velocity vector $(\bar{q})$ and the pressure are chosen as follows.

$$
\bar{q}=[u(x, y) \hat{i}+v(x, y) \hat{j}] e^{i w t} \text { and } \mathrm{P}(\mathrm{x}, \mathrm{y})=\mathrm{p}(\mathrm{x}, \mathrm{y}) \mathrm{e}^{\mathrm{iwt}},
$$

where $\mathrm{u}(\mathrm{x}, \mathrm{y})$ and $\mathrm{v}(\mathrm{x}, \mathrm{y})$ are the velocity components of the flow along the coordinate directions of $(\mathrm{x}, \mathrm{y})$ respectively. Let $\mathrm{x}$ and $\mathrm{y}$ be the coordinate axes parallel and perpendicular to the channel walls.

Equation of continuity

$$
\frac{\partial u}{\partial x}+\frac{\partial v}{\partial y}=0
$$

Equation of Incompressibility for stratified incompressible flow

$$
\begin{aligned}
& \frac{d \rho}{d t} \equiv \frac{\partial \rho}{\partial t}+u \frac{\partial \rho}{\partial x}+v \frac{\partial \rho}{\partial y}=0 \\
& \text { Equation of Motion } \\
& \rho\left(\frac{\partial u}{\partial t}+u \frac{\partial u}{\partial x}+v \frac{\partial u}{\partial y}\right)=-\frac{\partial \mathrm{p}}{\partial \mathrm{x}}+\mu\left(\frac{\partial^{2} u}{\partial x^{2}}+\frac{\partial^{2} u}{\partial y^{2}}\right) \\
& \rho\left(\frac{\partial v}{\partial t}+u \frac{\partial v}{\partial x}+v \frac{\partial v}{\partial y}\right)=-\frac{\partial \mathrm{p}}{\partial y}+\mu\left(\frac{\partial^{2} v}{\partial x^{2}}+\frac{\partial^{2} v}{\partial y^{2}}\right)-\rho \mathrm{g}
\end{aligned}
$$

Here $\mu$ represents the coefficient of viscosity and $\rho$ the density of the fluid

The density distribution in the undisturbed state is taken as

$\rho=\rho_{0}(y)+\rho^{\prime}(y, t)$ 
Where

$$
\rho_{0}(y)=\rho_{0}{ }^{\prime}(1-\beta y)
$$

$\rho_{0}^{\prime}$ is a constant, density, $\rho_{0}(y)$ is linearly distributed, $\rho^{\prime}(y, t)$ is perturbation density, $\beta$ stratification parameter (a constant) so that Brunt - Vaisala frequency $\mathrm{N}$ becomes $N^{2}=\beta g$ and the Reynold's number is given by

$$
\operatorname{Re}=\frac{\rho U^{2}}{L} / \frac{\mu u}{L^{2}}=\frac{\rho L U}{\mu}=\frac{U L}{v} \quad\left(\text { where } v=\frac{\mu}{\rho}\right)
$$

This is called stokes flow when $\operatorname{Re}$ is small $\operatorname{Re}<<1$, the flow is called stokes flow or small Reynolds's number flow or creeping flow.

For Stokes' flow (3) and (4) becomes

$$
\begin{aligned}
& \rho \frac{\partial u}{\partial t}=-\frac{\partial p}{\partial x}+\mu\left(\frac{\partial^{2} u}{\partial x^{2}}+\frac{\partial^{2} u}{\partial y^{2}}\right) \\
& \rho \frac{\partial v}{\partial t}=-\frac{\partial p}{\partial y}+\mu\left(\frac{\partial^{2} v}{\partial x^{2}}+\frac{\partial^{2} v}{\partial y^{2}}\right)-\rho \mathrm{g} \\
& \frac{\partial \rho^{\prime}}{\partial t}=\rho_{0}^{\prime} \beta v
\end{aligned}
$$

We use Bousenesq's approximation in the inertial terms which means

$$
\begin{aligned}
& \rho_{0}^{\prime} \frac{\partial u}{\partial t}=-\frac{\partial \mathrm{p}}{\partial \mathrm{x}}+\mu\left(\frac{\partial^{2} u}{\partial x^{2}}+\frac{\partial^{2} u}{\partial y^{2}}\right) \\
& \rho_{0}{ }^{\prime} \frac{\partial v}{\partial t}=-\frac{\partial \mathrm{p}}{\partial \mathrm{y}}+\mu\left(\frac{\partial^{2} v}{\partial x^{2}}+\frac{\partial^{2} v}{\partial y^{2}}\right)-\rho^{\prime} \mathrm{g}
\end{aligned}
$$

Differentiating (10) and (11) with respect to $t$

$$
\begin{aligned}
& \rho_{0}{ }^{\prime} \frac{\partial^{2} u}{\partial t^{2}}=-\frac{\partial^{2} \mathrm{p}}{\partial \mathrm{t} \partial \mathrm{x}}+\mu \frac{\partial}{\partial t}\left(\frac{\partial^{2} u}{\partial x^{2}}+\frac{\partial^{2} u}{\partial y^{2}}\right) \\
& \rho_{0}{ }^{\prime} \frac{\partial^{2} v}{\partial t^{2}}=-\frac{\partial^{2} \mathrm{p}}{\partial \mathrm{t} \partial \mathrm{y}}+\mu \frac{\partial}{\partial t}\left(\frac{\partial^{2} v}{\partial x^{2}}+\frac{\partial^{2} v}{\partial y^{2}}\right)-\mathrm{g} \frac{\partial \rho^{\prime}}{\partial t}
\end{aligned}
$$

Using (9) in (13)

$$
\rho_{0}^{\prime} \frac{\partial^{2} v}{\partial t^{2}}=-\frac{\partial^{2} \mathrm{p}}{\partial \mathrm{t} \partial \mathrm{y}}+\mu \frac{\partial}{\partial t}\left(\frac{\partial^{2} v}{\partial x^{2}}+\frac{\partial^{2} v}{\partial y^{2}}\right)-(\beta \mathrm{g}) \rho_{0}{ }^{\prime} \mathrm{v}
$$

The boundary conditions of the problem are

$$
\begin{aligned}
& \mathrm{u}(\mathrm{x}, 0)=0, \mathrm{u}(\mathrm{x}, \mathrm{h})=0 \\
& \mathrm{v}(\mathrm{x}, 0)=\mathrm{v}_{1}, \mathrm{v}(\mathrm{x}, \mathrm{h})=\mathrm{v}_{2}
\end{aligned}
$$

Differentiating (12) Partially with respect to y

$$
\rho_{0}{ }^{\prime} \frac{\partial^{2}}{\partial t^{2}}\left(\frac{\partial u}{\partial y}\right)=-\frac{\partial^{2} \mathrm{p}}{\partial \mathrm{t} \partial \mathrm{x} \partial \mathrm{y}}+\mu \frac{\partial}{\partial t} \nabla^{2}\left(\frac{\partial \mathrm{u}}{\partial \mathrm{y}}\right)
$$

Note: $\frac{\partial^{2}}{\partial x^{2}}+\frac{\partial^{2}}{\partial y^{2}}=\nabla^{2}$
Differentiating (14) Partially with respect to $\mathrm{x}$

$$
\rho_{0}{ }^{\prime} \frac{\partial^{2}}{\partial t^{2}}\left(\frac{\partial v}{\partial x}\right)=-\frac{\partial^{2} \mathrm{p}}{\partial \mathrm{t} \partial \mathrm{x} \partial \mathrm{y}}+\mu \frac{\partial}{\partial t} \nabla^{2}\left(\frac{\partial \mathrm{v}}{\partial x}\right)-\beta \mathrm{g} \rho_{0}{ }^{\prime} \frac{\partial \mathrm{v}}{\partial \mathrm{x}}
$$

Subtracting (16) from (15), we get

$\rho_{0}{ }^{\prime} \frac{\partial^{2}}{\partial t^{2}}\left(\frac{\partial u}{\partial y}-\frac{\partial v}{\partial x}\right)=\mu \frac{\partial}{\partial t} \nabla^{2}\left(\frac{\partial u}{\partial y}-\frac{\partial \mathrm{v}}{\partial x}\right)+\beta \mathrm{g} \rho_{0}{ }^{\prime} \frac{\partial \mathrm{v}}{\partial \mathrm{x}}$

We define Stream Function $\psi$ such that

$u=\frac{\partial \psi}{\partial y}$ and $\quad v=-\frac{\partial \psi}{\partial x}$

Equation (17) becomes

$\rho_{0} \cdot \frac{\partial^{2}}{\partial t^{2}} \nabla^{2} \psi=\mu \frac{\partial}{\partial t} \nabla^{4} \psi-N^{2} \rho_{0}{ }^{\prime} \frac{\partial^{2} \psi}{\partial x^{2}}$

Put $\psi(x, y, t)=\Psi(x, y) e^{i \omega t}$

$u=u(x, y) e^{i \omega t}, \quad \mathrm{v}=\mathrm{v}(\mathrm{x}, \mathrm{y}) e^{i \omega t}$, and $p=p(x, y) e^{i \omega t}$

Equation (19) becomes

$\left(\nabla^{2}-\frac{i \rho_{0}{ }^{\prime} \omega}{\mu}\right) \nabla^{2} \Psi-\frac{N^{2} \rho_{0}{ }^{\prime}}{\mu i \omega} \frac{\partial^{2} \Psi}{\partial \mathrm{x}^{2}}=0$

The function $f(\eta)$ is introduced as follows ( by Sellars [16]):

$\Psi=h\left(\frac{u_{0}}{a}-\frac{v_{2} x}{h}\right) \mathrm{f}(\eta)$

Where $\eta=\frac{y}{h}, \mathrm{a}=1-\frac{v_{1}}{v_{2}}, \quad 0 \leq \mathrm{v}_{1} \leq \mathrm{v}_{2}$ and $\mathrm{u}_{\mathrm{o}}$ is the average entrance velocity.

From Equation (21)

$\nabla^{4} \Psi=\frac{1}{h^{3}}\left(\frac{u_{0}}{a}-\frac{v_{2} x}{h}\right) f^{i v}(\eta)$

$\frac{\partial^{2} \Psi}{\partial x^{2}}=0$

Substituting the above in equation (20)

$\left(D^{4}-\frac{i \rho_{0}{ }^{\prime} \omega}{\mu} h^{2} D^{2}\right) f(\eta)=0$

where $\mathrm{D}^{2}=\frac{d^{2}}{d \eta^{2}}$.

Equation (22) is a differential equation of order 4 with constant co-efficient for which the solution is given by

Auxiliary Equation

$m^{4}-\frac{i \rho_{0}{ }^{\prime} \omega}{\mu} h^{2} m^{2}=0$

Solving we get

$m=0,0, \pm \sqrt{\frac{i \rho_{0}{ }^{\prime} \omega}{\mu}} h$ 
$m=0,0, \pm \sqrt{\frac{\rho_{0}{ }^{\prime} \omega}{\mu}} \frac{(1+i)}{\sqrt{2}} h \quad$ where $\sqrt{i}= \pm \frac{(1+i)}{\sqrt{2}}$

$m=0,0, \pm \alpha h \quad$ where $\alpha=\frac{1}{\sqrt{2}} \sqrt{\frac{\rho_{0}{ }^{\prime} \omega}{\mu}}(1+i)=a_{1}(1+i)$

and $a_{1}=\frac{1}{\sqrt{2}} \sqrt{\frac{\rho_{0}{ }^{\prime} \omega}{\mu}}$

Therefore the General Solution of equation (22) is given by

$f(\eta)=c_{1}+c_{2} \eta+c_{3} e^{\alpha h \eta}+c_{4} e^{-\alpha h \eta}$

The Boundary Conditions are transformed in terms of $f(\eta)$ are as follows

$f(0)=1-a, f(1)=1$ and $f^{\prime}(0)=f^{\prime}(1)=0$

The result obtained by applying the boundary conditions on $\mathrm{f}(\eta)$, are

$\mathrm{f}(0)=1-\mathrm{a}=\mathrm{c}_{1}+\mathrm{c}_{3}+\mathrm{c}_{4}$

$\mathrm{f}(1)=1=\mathrm{c}_{1}+\mathrm{c}_{2}+\mathrm{c}_{3} \mathrm{e}^{\mathrm{ah}}+\mathrm{c}_{4} \mathrm{e}^{-\mathrm{ah}}$

$\mathrm{f}^{\prime}(0)=0=\mathrm{c}_{2}+\alpha \mathrm{h} \mathrm{c}_{3}-\alpha \mathrm{h} \mathrm{c}_{4}$

and $f^{\prime}(1)=0=c_{2}+\alpha h c_{3} e^{\alpha h}-\alpha h c_{4} e^{-\alpha h}$

Solving the above equations, the values of the constants are as follows.

$$
\begin{aligned}
& c_{1}=1-a-\frac{a\left(e^{\alpha h}+e^{-\alpha h}-2\right)}{4+e^{\alpha h}(\alpha h-2)-e^{-\alpha h}(2+\alpha h)} \\
& c_{2}=\frac{\alpha h a\left(e^{\alpha h}-e^{-\alpha h}\right)}{4+e^{\alpha h}(\alpha h-2)-e^{-\alpha h}(\alpha h+2)} \\
& c_{3}=\frac{a\left(e^{-\alpha h}-1\right)}{4+e^{\alpha h}(\alpha h-2)-e^{-\alpha h}(\alpha h+2)} \\
& c_{4}=\frac{a\left(e^{\alpha h}-1\right)}{4+e^{\alpha h}(\alpha h-2)-e^{-\alpha h}(\alpha h+2)}
\end{aligned}
$$

Now to separate the above constants into real and imaginary parts, let us consider

$4+e^{\alpha h}(\alpha h-2)-e^{-\alpha h}(\alpha h+2)=A+i B$ (say)

where $\alpha=\frac{1}{\sqrt{2}} \sqrt{\frac{\rho_{0}{ }^{\prime} \omega}{\mu}}(1+i)=a_{1}(1+i)$ and $a_{1}=\frac{1}{\sqrt{2}} \sqrt{\frac{\rho_{0}{ }^{\prime} \omega}{\mu}}$

$$
\begin{aligned}
& A+i B=4+e^{\alpha h}(\alpha h-2)-e^{-\alpha h}(\alpha h+2) \\
& =4+e^{(1+i) a_{1} h}\left((1+i) a_{1} h-2\right)-e^{-(1+i) a_{1} h}\left(2+(1+i) a_{1} h\right) \\
& =4+e^{a_{1} h} e^{i a_{1} h}\left(a_{1} h+i a_{1} h-2\right)-e^{-a_{1} h} e^{-i a_{1} h}\left(2+a_{1} h+i a_{1} h\right) \\
& =4+e^{a_{1} h}\left(\cos a_{1} h+i \sin a_{1} h\right)\left(\left(a_{1} h-2\right)+i a_{1} h\right) \\
& \quad-e^{-a_{1} h}\left(\cos a_{1} h-i \sin a_{1} h\right)\left(\left(2+a_{1} h\right)+i a_{1} h\right) \\
& =4+e^{a_{1} h}\left(\left(a_{1} h-2\right) \cos a_{1} h-a_{1} h \sin a_{1} h\right) \\
& \quad-e^{-a_{1} h}\left(\left(a_{1} h+2\right) \cos a_{1} h+a_{1} h \sin a_{1} h\right)
\end{aligned}
$$
$+i\left(e^{a_{1} h}\left(a_{1} h \cos a_{1} h-\left(a_{1} h-2\right) \sin a_{1} h\right)-e^{-a_{1} h}\left(a_{1} h \cos a_{1} h-\left(a_{1} h+2\right) \sin a_{1} h\right)\right)$ determined.

$=R_{2}+i I_{2}$

$$
\begin{aligned}
& C_{3}=\frac{a\left(e^{-\alpha h}-1\right)}{A+i B} \\
& =\frac{a}{A^{2}+B^{2}} e^{-a_{1} h}\left(A \cos a_{1} h-B \sin a_{1} h\right)-A \\
& \quad-i\left(\frac{a}{A^{2}+B^{2}}\left(e^{-a_{1} h}\left(A \sin a_{1} h+B \cos a_{1} h\right)-B\right)\right) \\
& =R_{3}+i I_{3} \\
& C_{4}=-e^{\alpha h} C_{3} \\
& =-e^{a_{1} h}\left(R_{3} \cos a_{1} h-I_{3} \sin a_{1} h\right)-i e^{a_{1} h}\left(R_{3} \sin a_{1} h+I_{3} \cos a_{1} h\right) \\
& =R_{4}+i I_{4}
\end{aligned}
$$$$
\mathrm{f}(\eta)=\mathrm{R}_{1}+\mathrm{iI}_{1}+\left(\mathrm{R}_{2}+\mathrm{iI}_{2}\right) \eta
$$$$
+\left(\mathrm{R}_{3}+\mathrm{iI}_{3}\right)\left(\mathrm{e}^{\mathrm{a}_{1} \mathrm{~h} \eta}\left(\cos a_{1} h \eta+i \sin a_{1} h \eta\right)\right)
$$$$
+\left(\mathrm{R}_{4}+\mathrm{iI}_{4}\right)\left(\mathrm{e}^{-\mathrm{a}_{1} \mathrm{~h} \eta}\left(\cos a_{1} h \eta-i \sin a_{1} h \eta\right)\right)
$$$$
=\mathrm{R}_{1}+\mathrm{R}_{2} \eta+\mathrm{R}_{3} \mathrm{e}^{\mathrm{a}_{1} \mathrm{~h} \eta} \cos a_{1} h \eta-\mathrm{I}_{3} \mathrm{e}^{\mathrm{a}_{1} \mathrm{~h} \eta} \sin a_{1} h \eta
$$$$
+\mathrm{R}_{4} \mathrm{e}^{-\mathrm{a}_{1} \mathrm{h \eta}} \cos a_{1} h \eta+\mathrm{I}_{4} \mathrm{e}^{-\mathrm{a}_{1} \mathrm{~h} \eta} \sin a_{1} h \eta
$$$$
+i\left(\begin{array}{l}
\mathrm{I}_{1}+\mathrm{I}_{2} \eta+\mathrm{R}_{3} \mathrm{e}^{\mathrm{a}_{1} \mathrm{~h} \eta} \sin a_{1} h \eta+\mathrm{I}_{3} \mathrm{e}^{\mathrm{a}_{1} \mathrm{~h} \eta} \cos a_{1} h \eta \\
+\mathrm{I}_{4} \mathrm{e}^{-\mathrm{a}_{1} h \eta} \cos a_{1} h \eta-\mathrm{R}_{4} \mathrm{e}^{-\mathrm{a}_{1} h \eta} \sin a_{1} h \eta
\end{array}\right)
$$$$
=f_{1}(\eta)+i f_{2}(\eta)
$$

Substituting the value of $f(\eta)=c_{1}+c_{2} \eta+c_{3} e^{\alpha h \eta}+c_{4} e^{-\alpha h \eta}$ in (21), the stream function is calculated. Using the expression for $\psi$ and equation (18), the velocity components

\section{Therefore}




$$
\begin{gathered}
u=\left(\frac{u_{0}}{a}-\frac{v_{2} x}{h}\right)\left(f_{1}^{\prime}(\eta) \cos \omega t-f_{2}^{\prime}(\eta) \sin \omega t\right) \\
+i\left(\frac{u_{0}}{a}-\frac{v_{2} x}{h}\right)\left(f_{1}^{\prime}(\eta) \sin \omega t+f_{2}^{\prime}(\eta) \cos \omega t\right) \\
v=v_{2}\left(f_{1}(\eta) \cos \omega t-f_{2}(\eta) \sin \omega t\right) \\
+i v_{2}\left(f_{1}(\eta) \sin \omega t+f_{2}(\eta) \cos \omega t\right)
\end{gathered}
$$

\section{PRESSURE DiSTRIBUTION}

The result obtained from equations (10), (11) and (21) are

$\frac{\partial p}{\partial x}=-i \rho_{0}^{\prime} \omega\left(\frac{u_{0}}{a}-\frac{v_{2} x}{h}\right) f^{\prime}(\eta)+\frac{\mu}{h^{2}}\left(\frac{u_{0}}{a}-\frac{v_{2} x}{h}\right) f^{\prime \prime \prime}(\eta)$

$\frac{\partial p}{\partial y}=-\rho_{0}{ }^{\prime} \omega_{i v_{2}} f(\eta)+\frac{\mu v_{2}}{h^{2}} f^{\prime \prime}(\eta)-\rho_{0}^{\prime} g$

By the definition of total differentiation,

$\mathrm{d} p=\frac{\partial \mathrm{p}}{\partial \mathrm{x}} \mathrm{dx}+\frac{\partial \mathrm{p}}{\partial \mathrm{y}} \mathrm{dy}$

$\Rightarrow d p=\left(\frac{u_{0}}{a}-\frac{v_{2} x}{h}\right)\left(-\rho \omega i f^{\prime}(\eta)+\frac{\mu}{h^{2}} f^{\prime \prime \prime}(\eta)\right) d x$

$+v_{2}\left(-\rho \omega\right.$ i $\left.f(\eta)+\frac{\mu}{h^{2}} f^{\prime \prime}(\eta)-\rho_{0}^{\prime} g\right) d y$

Integrating the above equation, the result obtained is

$$
\begin{gathered}
p=\left(\frac{u_{0} x}{a}-\frac{v_{2} x^{2}}{2 h}\right)\left(-\rho \omega i f^{\prime}(\eta)+\frac{\mu}{h^{2}} f^{\prime \prime \prime}(\eta)\right) \\
-\rho \omega i v_{2} \int_{0}^{\eta} f(\eta) d \eta+\frac{\mu v_{2}}{h^{2}} f^{\prime}(\eta)-\rho_{0}{ }^{\prime} g h \eta \\
p(x, \eta)=c_{5}\left(\frac{u_{0}}{a}-\frac{v_{2} x}{2 h}\right) x+\frac{\mu v_{2}}{h^{2}} f^{\prime}(\eta) \\
-\rho \omega i v_{2} \int_{0}^{\eta} f(\eta) d \eta-\rho_{0}^{\prime} g h \eta
\end{gathered}
$$

$\mathrm{c}_{5}=\frac{\mu}{h^{2}} \mathrm{f}^{\prime \prime \prime}(\eta)-\mathrm{i} \rho \omega \mathrm{f}^{\prime}(\eta)$

The arbitrary constant $\mathrm{c}_{5}$ is obtained as

$\mathrm{c}_{5}=\frac{\mu}{h^{2}} \mathrm{f}^{\prime \prime \prime}(0)$ when $\eta=0$, since $\mathrm{f}^{\prime}(0)=0$

The pressure drop is given by $\mathrm{p}(\mathrm{x}, \eta)-\mathrm{p}(0,0)=$

$k_{1}\left(\frac{u_{0}}{a}-\frac{v_{2} x}{2 h}\right) x+\frac{\mu v_{2}}{h^{2}} f^{\prime}(\eta)-\rho \omega i v_{2} \int_{0}^{\eta} f(\eta) d \eta-\rho_{0}{ }^{\prime} g h \eta$

\section{RESULTS AND DISCUSSION}

The numerical values of $\mathrm{u}$ (x-direction) and $\mathrm{v}$ (y-direction) velocity profiles have been calculated for different values of $\mathrm{x}$ and $y$. It is assumed that $0 \leq x \leq 4$ and $0 \leq y \leq 10$. Figures 1,2 and 3 are the axial velocity profiles at different cross sections of the channel namely at $\mathrm{x}=0, \mathrm{x}=2$ and $\mathrm{x}=4, \mathrm{~h}=10, \mathrm{a}=0.5$, $\mathrm{v}_{1}=1, \mathrm{v}_{2}=2$ when the average entrance velocity is $\mathrm{u}_{0}=0.5$. From the above figures it is seen that the magnitude of the axial velocity decreases as $\mathrm{x}$ increases from 0 to 4 for different values of $\omega \mathrm{t}$. The Figure 4 represents the axial velocity profiles of $u$ at $x=0, h=10, a=0.5, v_{1}=1, v_{2}=2$ when the inlet velocity is increased to $\mathrm{u}_{0}=1$ from $\mathrm{u}_{0}=0.5$. It is clearly seen that the magnitudes of the axial velocity $u$ are more when the value of the inlet velocity is increased to $u_{0}=1.0$ or 2.0 for different values of wt. It is also seen that in Figure 5, the radial velocity vanishes for $\mathrm{wt}=\frac{\pi}{2}$ and the radial velocity profiles are nonlinear for the other values of wt. The above is true for all different values of $v_{2}$. The Figure 6 represents the axial velocity profiles at different values of $\mathrm{x}$, namely $\mathrm{x}=0,1,2,3,4$ when the average entrance velocity is $\mathrm{u}_{0}=0.5$. We see that the profiles are parabolic for different values of $\mathrm{x}$. The Figure 7 represents the radial velocity profile for different values of $v_{2}$ when $\mathrm{wt}=0$. The Figure 8 represents the axial velocity profiles for different values of $\mathrm{u}_{0}=0.5,1.0,1.5,2.0,2.5$ when $\mathrm{wt}=0, \mathrm{~h}=10$ and $\mathrm{x}=0$. Here also we see that the profiles are parabolic for different values of $\mathrm{u}_{0}$.

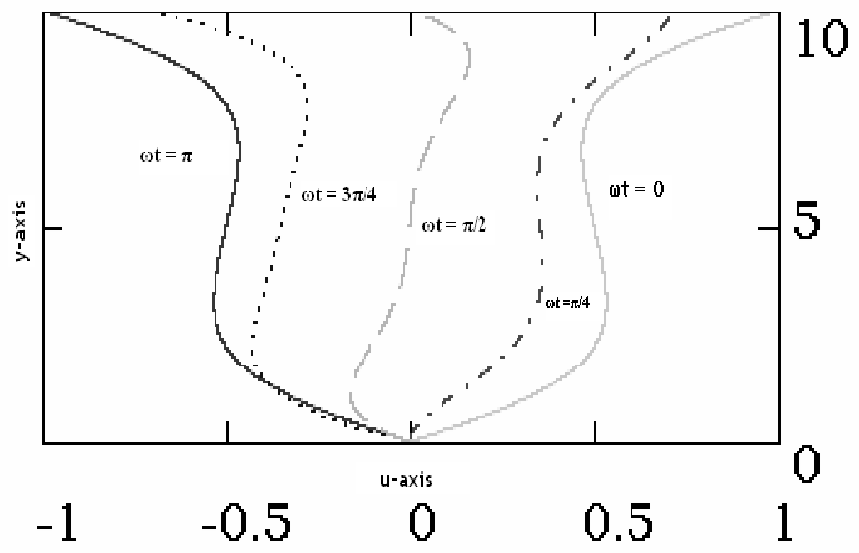

Figure 1: Axial Velocity Profiles for $\mathrm{x}=0, \mathrm{~h}=10$ and $\mathrm{uo}=0.5$ for Different Values of $\omega t$

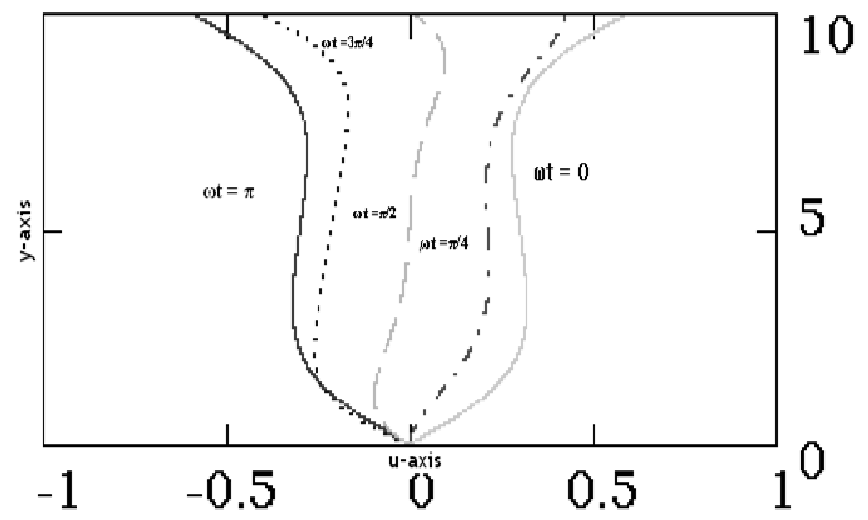

Figure 2: Axial velocity Profiles for $\mathrm{x}=2, \mathrm{~h}=10$ and $\mathrm{uo}=0.5$ for Different Values of $\omega t$ 


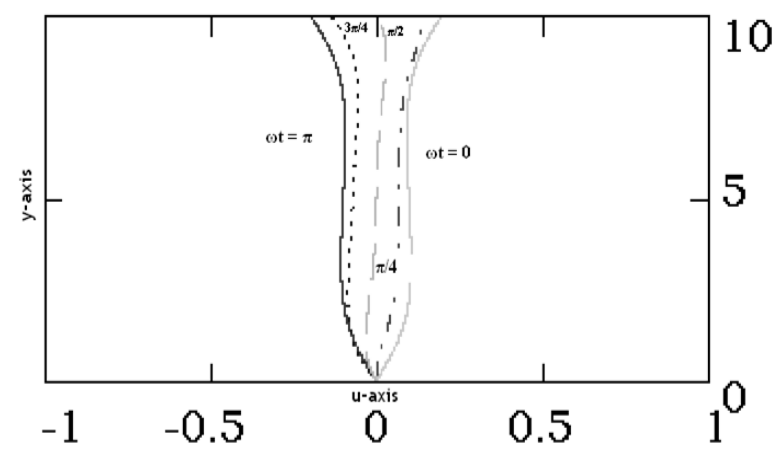

Figure 3: Axial Velocity Profiles for $\mathrm{x}=4, \mathrm{~h}=10$ and $\mathrm{uo}=0.5$ for Different Values of $\omega t$

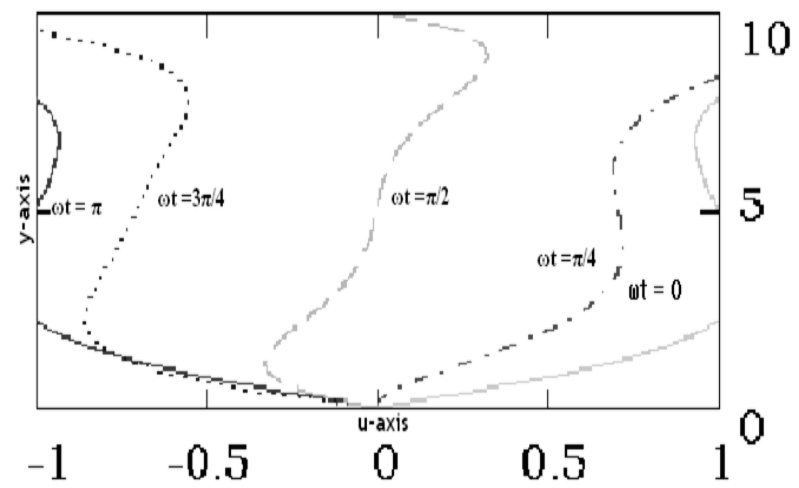

Figure 4: Axial Velocity Profiles for $\mathrm{x}=0, \mathrm{~h}=10$ and $\mathrm{uo}=1.0$ for Different Values of $\omega \mathrm{t}$

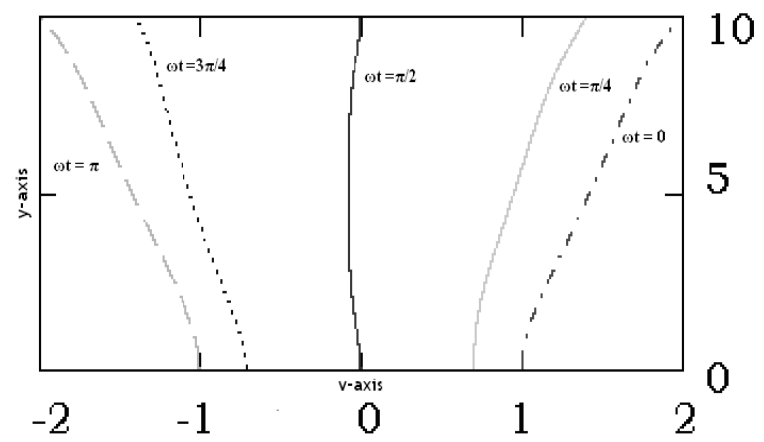

Figure 5: Transverse Velocity Profiles for $\mathrm{h}=10, \mathrm{a}=0.5$ and $\mathrm{v} 2=2$ for Dfferent Values of $\omega \mathrm{t}$

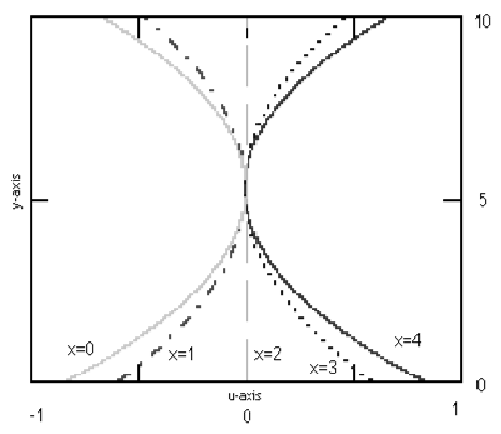

Figure 6: Axial Velocity Profiles for $\mathrm{u} 0=0.5, \mathrm{~h}=10$ and $\omega \mathrm{t}=0$ and for Different Values of $\mathrm{x}$

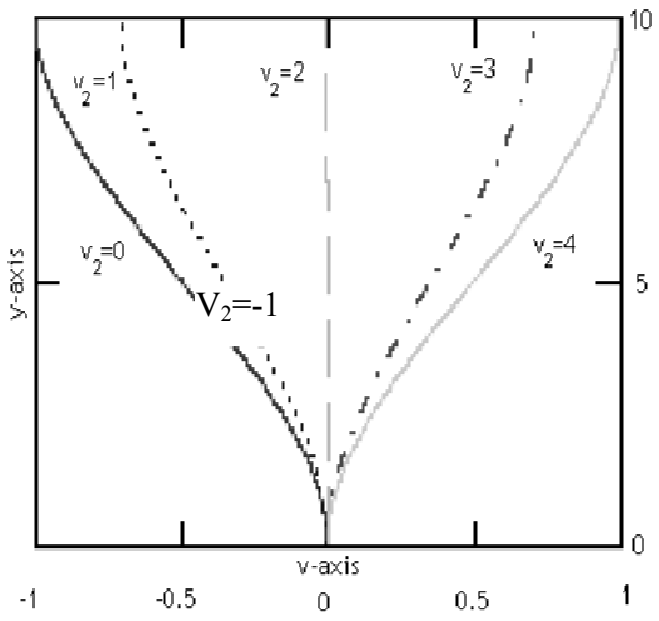

Figure 7: Transverse Velocity Profiles for $\mathrm{a}=0.5, \mathrm{~h}=10$ and $\omega \mathrm{t}=0$ and for Different Values of $\mathrm{v} 2$

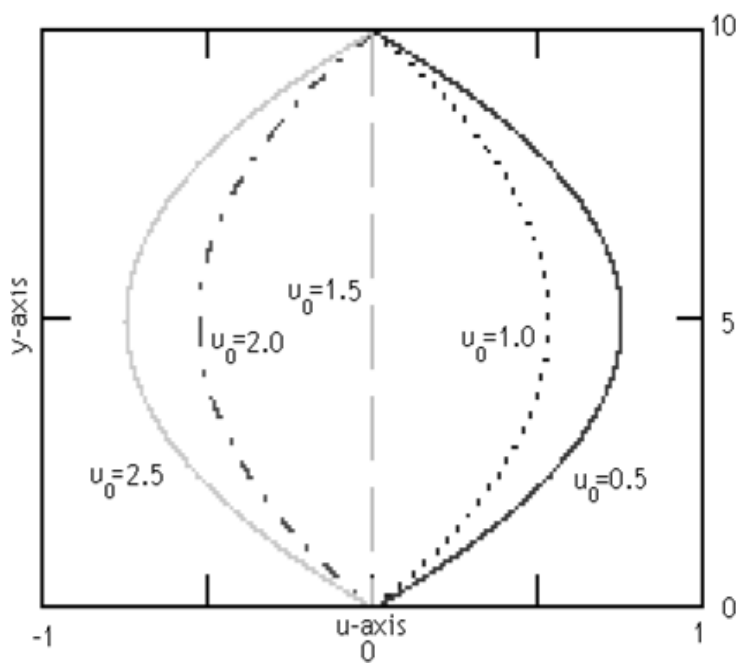

Figure 8: Axial Velocity Profiles for $\mathrm{u} 0=0.5,1.0,1.5,2.0$, 2.5, $\omega \mathrm{t}=0$ and when $\mathrm{x}=0, \mathrm{~h}=10$

\section{CONCLUSION}

In the above analysis a class of solutions of the Nonhomogeneous Oscillatory vertically stratified stokes flow of viscous fluid between two parallel porous plates is presented, when there exists variable suction or injection at the walls. The results presented here add one more class of exact solution S. Ganesh [8] Rajagopal [14], Wang [22] to that of a few presently available in literature. The result for the axial velocity obtained here reduces to the result for the axial velocity in the case of laminar flow between parallel plates (i.e., when $\mathrm{v}=0$ ). The effect of stratification is found in the pressure distribution.

\section{REFERENCES}

[1] E. Abo-El-Dhat, "Hartmann flow with uniform suction and injection at the bounding plates", MS Thesis, Helwan University, Egypt, 1993.

[2] H.A. Attia, "Unsteady Hartmann flow with heat transfer of a viscoelastic fluid considering the Hall Effect", Canadian J. Phys. Rev. Can. Phys. Vol. 82, No. 2, Pp. 127-139, 2004.

[3] H.A. Attia, "The effect of suction and injection on the unsteady flow between two parallel plates with variable properties", Tamkang Journal of Science and Engg. Vol. 8, Pp. 17-22, 2005. 
[4] A.S. Berman.A.S, "Laminar flow in channels with porous walls", J. Appl. Phys. Vol. 24, Pp.1232-1235, 1953.

[5] I.C.Bagchi, "Unsteady flow of viscoelastic Maxwell fluid with transient pressure gradient through a rectangular channel", Ind. J. Mech. Math. $4,2,1996$.

[6] D. G.Drake "On the flow in a channel due to periodic pressure gradient", Quart.J. Mech. Appl . Math. Vol. 18, Pp. 1-10, 1965.

[7] M.C. Hendershot, "Impulsively started oscillations in a rotating stratified fluid”, J. Fluid Mech. Vol. 38, Pp. 513-527, 1969.

[8] S.Krishnambal and S. Ganesh, "Unsteady stokes flow of viscous fluid between two parallel porous plates", National conference on Mathematical Modeling and Analysis (NCMMA 2004), BITS Pilani, Ch. 24, Pp. 214-221, 2004.

[9] D.V. Krishna, and L.V.K.V. Sharma, "Motion of an axisymmetric body in a rotating stratified fluid confined between two parallel planes", J. Fluid Mech. Vol. 38, Pp. 833-842, 1969.

[10] K.B.Naidu, "Stratified fluid flows", Ph.D. Thesis, 1973.

[11] K.B.Naidu "Stratified Viscous Flow between two Oscillating Cylinders", Indian Journal of Pure and Applied Mathematics, Indian National Science Academy, Vol.5, No.12, Pp. 1127-1136, 1974.

[12] R.L. Panton, "Incompressible flow", Second edition, J. Wiley, Newyork, 1996.

[13] V.S. Rao, and G.V.P. Rao, "On waves generated in rotating stratified liquids by travelling foreign effects", J. Fluid Mech. Vol.46, Pp. 447 464, 1971.

[14] K.R. Rajagopal, A.Z. Szeri, C.Y. Lai, "Asymmetric flow between parallel rotating disks", Journal of Fluid Mechanics, Vol. 146, Pp. 203225.

[15] L.V.K.V. Sharma, and K.B. Naidu, "Source in a rotating stratified fluid", Acta Mech. Vol. 13, Pp. 21-29, 1971.

[16] J.R.Sellars, "Laminar flow in channels with porous walls at high suction Reynolds number", J.Appl.Phys, Vol. 26, 1955.

[17] Terrill, R.M, "Laminar flow in a uniformly porous channel". The Aeronautical Quarterly 15, Pp. 299-310, 1964.

[18] R.M. Terill, and G.M. Shreshta, "Laminar flow through parallel and uniformly porous walls of different permeability", Zamp, Vol. 16, Pp. $470,1965$.

[19] I. Tani, "Steady motion of electrically conducting and viscous fluids in channels", J. Aerospace sci, Vol. 29, Pp. 287, 1962.

[20] S.W.Yuan, "Further investigations of laminar flow in channels with porous walls", J. appl. Phys, Vol. 27, Pp. 267, 1956.

[21] M.B.Zaturska, P.G. Drazin, W.H.H. Banks, "On the flow of a viscous fluid driven along a channel by suction at porous walls", Fluid Dyn. Res. Vol. 4, Pp. 151-178, 1988.

[22] C.Y. Wang, "Exact solutions of the steady-state Navier-Stokes equations", Annual Review of Fluid Mechanics, Vol. 23, Pp. 159-177, 1991.

[23] F.M. White, "Viscous fluid flow", Second ed., Mcgraw-Hill company, New York, 1991.

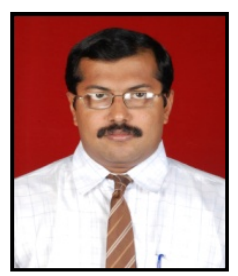

L. Prasanna Venkatesh born at Thippirajapuram (Kumbakonam district, TamilNadu, INDIA) on $30^{\text {th }}$ July 1979. He did his under graduation B.Sc (1999) ., and post graduations M.Sc (2001)., and M.Phil (2003)., in Mathematics in A.M. Jain College at Meenambakkam, Chennai, INDIA. He is currently doing Ph.D., in the field of fluid dynamics at Sathyabama University, Chennai, INDIA. $\mathrm{He}$ is currently working as Asst Professor, Dept of Mathemativcs, Sathyabama University, and has a teaching experience of 10 years in both UG and PG courses. His present research is in the area of stratified flows. 